\title{
Experimental Research on Hysteretic Behaviors of Square Tubular T-joint
}

\author{
Peng Deng ${ }^{1,}$, Benbing $\mathrm{Li}^{1, \mathrm{~b}}$, ,Huiling Wang ${ }^{1, \mathrm{c}}$,Qibiao Zhang ${ }^{2, \mathrm{~d}}$ \\ ${ }^{1}$ College of Civil Engineering, Shandong University of Science and Technology \\ Qingdao, Shandong 266590, China \\ 2 Jining Dongfang Construction Engineering Supervision Co., Ltd, Jining, 272000, China \\ a dengpeng1226@163.com, ${ }^{b}$ libenbing1234@163.com, ${ }^{\text {c }}$ drawingfish@qq.com \\ d1161218295@qq.com
}

Keywords: Square Tubular; T-Joints; Hysteretic Behavior; Cyclic Loading; Skeleton Curve

\begin{abstract}
In order to study the failure modes and hysteretic behaviors of square tubular T-joints, three specimens were made to conduct the cyclic loading test. The test stimulated the constrain condition with hinge connection of both ends of chord member, and the brace was subjected to axial cyclic loading. Based on the experiment, the specimen consisting of small-geometry brace showed a good ductility compared with the big one, and the obvious plastic deformation occurred at the intersection between chord and brace member, finally the welding was failure. However, the specimen consisting large-size brace appeared a large deformation on the side wall of chord member. In addition, due to the poor ductility of welding on the plates contained in chord member, the welding fracture on the intersection between upper flange and web plates leaded to test end for all the specimens.
\end{abstract}

\section{Introduction}

Steel tube structure can be used in variety architectural appearance with large span [1]. So, various references can be found related to steel tube structure. References [2] [4] indicated that the commonly failure modes were local large plasticity deformation on the chord surface, while the specimens were subjected to axial loading, or axial loading accompanied with bending moment. Reference [5] researched on multilinear kinematic hardening model, isotropic hardening model by finite element analysis, and the following conclusion was that it was effective to use multilinear kinematic hardening model studying on steel tube. References [6] [7] studied on full-width and stepped K-type gapped RHS-joints by finite element analysis, the effects of geometry parameters on joints deformation, stiffness and ultimate capacity were investigated. Reference [8] conducted a cyclic loading test on full-scale welded T-type and N-type joints, the conclusion was that the fracture occurred in welding of brace and chord intersection. References [9] [10] researched on failure mode and ultimate strength of CR T-joints and K-joints with inner diaphragm, the failure mode of reinforced specimens were changed, so was the stress distribution. References [11] [13] conducted a series of tests on square tubular T-joints reinforced with collar plate, the tests revealed that the reinforced joints failed differently and strength improved greatly.

Currently, the square tubular structure is widespread in domestic construction with a large section dimension and wall thickness, such as Bird's Nest and Shanghai International Circuit. However, most investigation is concentrated on static strength of square tubular T-joint. So, it's necessary to conduct cyclic loading test to study the hysteretic behaviors of square tubular T-joint.

\section{Experimental Program}

The experimental program consists three specimens and is summarized in Table 1 . The test is concentrated on the effect of width ratio $(\beta)$ between chord and brace member on hysteretic behaviors of square tubular T-joint. So diameter of braces is different while chords is same, the configuration and geometric variables of the specimens are illustrated in Fig.1. The specimens are 
made of Q235B steel which is commonly used in Chinese construction industry, and yielding strength is $f_{y}=251.4 \mathrm{~N} / \mathrm{mm}^{2}$, elasticity modulus is $\mathrm{E}=2.07 \times 10^{5} \mathrm{~N} / \mathrm{mm}^{2}$.

Table 1 Specimen detail

\begin{tabular}{cccccccc}
\hline Specimen & $l_{0}$ & $\begin{array}{c}\text { Chord } \\
d_{0}\end{array}$ & $t_{0}$ & $l_{1}$ & $\begin{array}{c}\text { Brace } \\
d_{1}\end{array}$ & $t_{1}$ & $\beta\left(d_{1} / d_{0}\right)$ \\
& $2,(\mathrm{~mm})$ & $(\mathrm{mm})$ & $(\mathrm{mm})$ & $(\mathrm{mm})$ & $(\mathrm{mm})$ & $(\mathrm{mm})$ & 0.4 \\
$\mathrm{~T} 250-100$ & 2500 & 250 & 8 & 400 & 100 & 4 & 0.6 \\
$\mathrm{~T} 250-150$ & 2,500 & 250 & 8 & 400 & 150 & 6 & 0.8 \\
T250-200 & 2,500 & 250 & 8 & 400 & 200 & 6 & \\
\hline
\end{tabular}

\section{Testing Setup, Loading System and Testing Content}

Both ends of chord member are set hinge connection while brace member are subjected to axial cyclic loading. The program adopts 50t reaction frame in disaster prevention and militation laboratory of Shandong University of Science and Technology, the test arrangement is shown in Fig.2. Before the actual test, two complete cyclic loads of $\pm 10 \mathrm{kN}$ are applied to check the working conditions of the strain gauges and other equipment. For each specimen, the brace load is applied at $25 \%, 50 \%$ and $75 \%$ of yield strength until specimen reaches yield. The yielding displacement $1 \Delta y$ is written down, and then cyclic axial displacement is applied to the brace end. The axial displacement at the brace end will be applied at $1 \Delta y, 2 \Delta y, 3 \Delta y$, and each displacement is looped three times. To measure the stress distribution nearby joints, some strain gauges are set near joints. A displacement meter is set at central bottom surface of chord member to measure the overall displacement of specimen, and another displacement meter is set at the top of brace to measure brace vertical displacement, then the difference between two displacement meters is the displacement of chord upper surface.

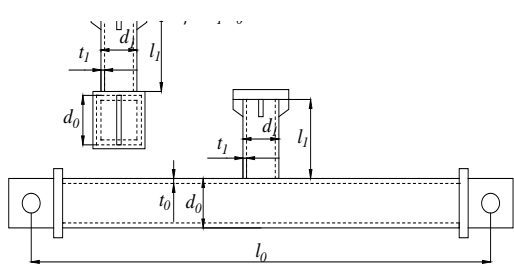

Fig.1 Schematic of T-joint

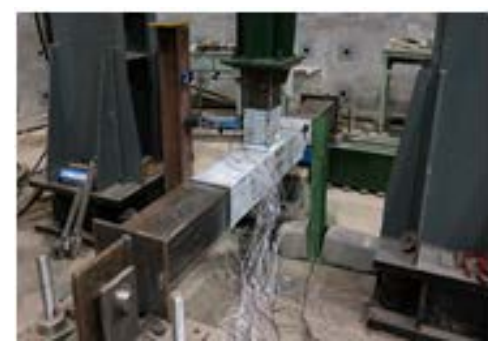

Fig.2 Testing setup of specimen

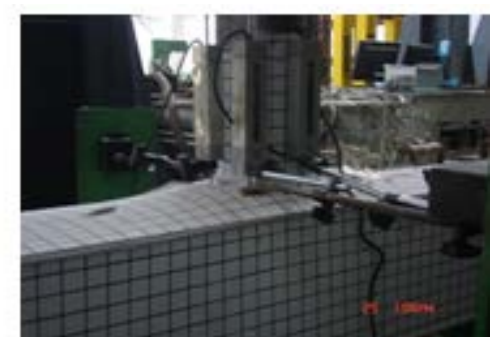

Fig.3 Specimen: T250-100

\section{Experiment Results and Analysis}

For the specimen of T250-100, upper surface of chord member reflected slightly buckling deformation while axial tension and compression increased to $93 \mathrm{kN}$, and yielding displacement $1 \Delta \mathrm{y}$ was written down. The welding of brace and chord intersection occurred slightly crack in the process of $1 \Delta y$, after the second circle of $2 \Delta y$, the chord surface reflected obviously buckling, which was shown in Fig.3. The welding fracture occurred at the intersection between upper flange and web plates of chord, then the test stopped.

For the specimen of T250-150, when actuator force increased to $110 \mathrm{kN}$, the center of the chord upper surface appeared slightly buckling which was shown in Fig.4. In the loading process of $1 \Delta y$, the upper flange and side wall of chord appeared obvious deformation, which was shown in Fig.5. At the beginning of $2 \Delta y$ process, the welding at the junction of upper flange and side wall appeared and developed quickly as shown in Fig.5, and test stopped.

For the specimen of T250-200, when the tensile strength increased to $315 \mathrm{kN}$, the chord bended obviously, but the side wall changed slightly. When brace was subjected to compression, the side wall of chord buckled suddenly, the welding cracked and the upper flange of chord deformed apparently, which could be seen in Fig. 6.

The hysteretic loops of specimen T250-100 are the plumpest of all, however, for specimen T250-200, which is obviously brittle failure. For all the specimens, only the specimens with small size brace showed good ductility, and the upper flange of chord around the brace deformed 
obviously, the specimens with large size brace mainly deformed on the side wall. All tests were stopped because of the crack of welding. So the welding quality is the most important factor to the ductility of welded square tubular T-joint.

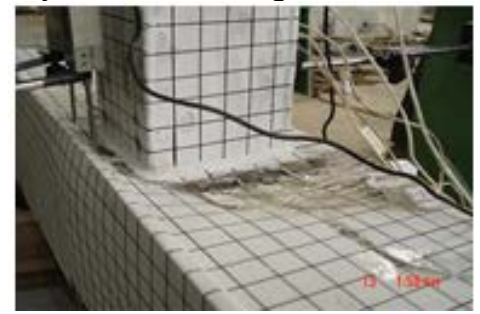

Fig.4 Specimen: T250-150

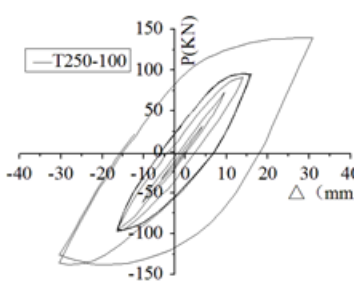

(a) $250-100$

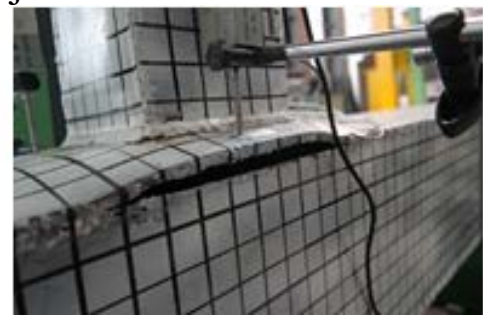

Fig.5 Specimen: T250-150

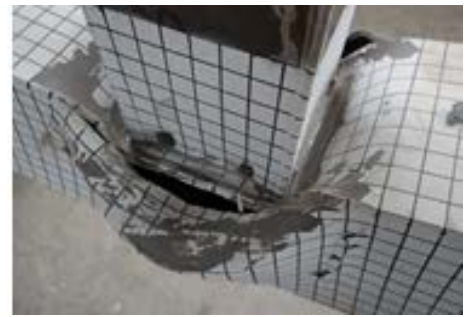

Fig.6 Specimen: T250-200

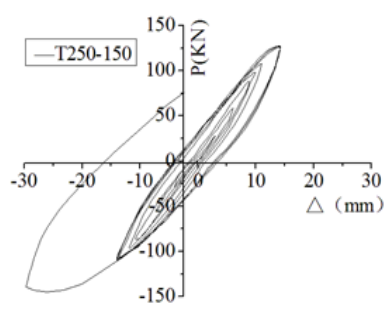

(b) T250-150

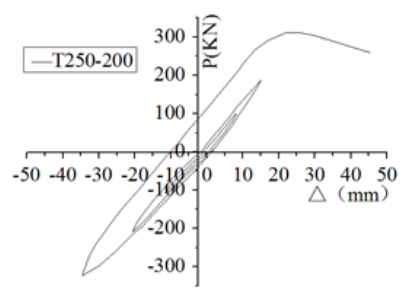

(c) T250-200

Fig.7 Hysteretic curves of specimens

\section{Analysis of Skeleton Curves and Bearing Capacity}

The skeleton curves of the specimens are obtained by joining the peak points in the loop of the hysteretic curves. The bearing load capacity, deformation and characteristics (such as energy dissipation, stiffness degradation and ductility) at different loading stage can be obtained from skeleton curve. The skeleton curves of T250-100, T250-150 and T250-200 are plotted in Fig. 8 respectively.

There will be obvious plastic deformation appearing on the upper surface of chord near brace and chord intersection when $\beta$ is small. However, when $\beta$ is big, the energy dissipation mainly depends on the buckling of the side wall, so the tensile strength on the brace leads to the crack of welding, and then the joint lose bearing capacity rapidly.

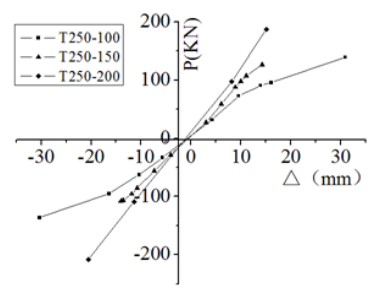

Fig.8 Skeleton curves of specimens

\section{Conclusion}

The results from the test on three welding square tubular T-joints as follow:

1. When the ratio of brace and chord diameters is smaller, the plastic deformation of upper flange has large contribution to energy dissipation of joint, and the joint shows satisfying ductility. When the ratio of brace and chord diameter is larger, the main deformation occurs on the side wall of chord, and the relativity deformations of upper flange can be ignored.

2. The welding quality has significant impact on the strength of welded square tubular, and the welding cracks rapidly under the cyclic loading. Therefore, the welding quality should be controlled for welded square tubular T-joint or certain reinforcement is essential. 


\section{References}

[1] Chen Yi-yi, Chen Yang-ji. the Status of Research of Steel Tubular Intersecting Joints [J]. Building Structure, 2002, 32(7): 52-55.

[2] Zhao X L, Hancock G.J., Plastic Mechanism Analysis of T-Joints in RHS Under Concentrate Force [R]. Report No.R644, Univ. of Sydney, 1991.

[3] Zhao X L, Hancock G.J., Plastic Mechanism Analysis of T-Joints in RHS Subjected to Combined Bending and Concentrated Force [R]. Report No.R673, Univ. of Sydney, Sydney, Australia, 1993.

[4] Zhao X L. Deformation Limit and Ultimate Strength of Welded T-joints in Cold-formed RHS Sections [J]. Journal of Constructional Steel Research, 2000, 127(10): 1173-1182.

[5] Goto, Y., Wang, Q., and Obata, M. FEM Analysis for Hysteretic Behavior of Thin-walled Steel Columns [J]. J.Struct. Engrg, ASCE, 1998, 124(11): 1290-1301.

[6] Wu Zhen-yu, Wu Sheng. Static Behavior of Full-Width K-type Gapped RHS-Joints Subjected to Combined Chord Axial Loading and Branch Axial Loading [J]. Building Science, 2004, 20(1): 14-19.

[7] Wu Zhen-yu, Wu Sheng. Static Behavior of Stepped K-type Gapped RHS-joints Subjected to Combined Chord Axial Loading and Branch Axial Loading [J]. Building Structure, 2004, 34(5): 14-17.

[8] He Yuan-bin, Hao Ji-ping Hysteretic Behavior of $\mathrm{T}$ and $\mathrm{N}$ joints [J]. Journal of Chongqing University, 2008, 31(7): 730-739.

[9] Deng Peng, Ma Zhang-yong, Liu Yan. Research on Failure Mode and Ultimate Strength of CR T-Joints and K-Joints with Inner Diaphragm ]. Journal of Kunming University of Science and Technology (Science and Technology), 2010, 35(6): 44-49.

[10] Deng Peng, Wang Lai. Research on Failure Mode of T-type RHS-CHS Joints with Inner Diaphragm [J]. Industrial Construction, 2011,41(12): 121-125.

[11] Shao Yong-bo, Wang Wen-jie, Chen Ying. Experimental Study on Hysteretic Behavior of Square Tubular T-Joints Reinforced with Collar Plate [J]. Journal of Southwest Jiaotong University, 2013, 48(1): 75-79.

[12] Lei Fei-yan, Shao Yong-bo, Xu Yan-hua. Hysteretic Analysis of Circular Tubular T-Joints with Chord Reinforcement [J]. J.of HUST. (Urban Science Edition), 2010, 27( 2): 78-81

[13] Shao Yong-bo, Yue Yong-sheng, Cai Yan-qing. Experimental Study on Hysteretic Behavior of Circular Tubular T-Joints Reinforced with Collar plate [J]. Engineering Mechanics, 2011, 28(10): 209-215.

[14] Industry Standard of PRC, Specificating of Testing Methods for Earthquake Resistant Building, (JGJ 101-96) [S]. China Architecture \&Building Press, 1997. 